\title{
LEGIONNAIRES DISEASE
}

\section{WHAT IS LEGIONNAIRES DISEASE?}

- Legionnaires disease is an infection of the lungs (pneumonia) caused by bacteria of the Legionella family.

- Most reported cases of Legionnaires disease in NSW are caused by Legionella pneumophila. In NSW every year about 70 cases of Legionnaires disease are notified.

- Legionella pneumophila is usually found in water sources, whereas another bacteria of the Legionella family, Legionella longbeachae is commonly found in soil and potting mix.

\section{WHAT ARETHE SYMPTOMS?}

- Legionnaires disease usually causes fever, chills and a cough that may be dry or may produce sputum. Some people also have muscle aches, headache, tiredness, loss of appetite and diarrhoea. People can become very sick with pneumonia; most people recover but the disease is occasionally fatal.

\section{HOW DO PEOPLE GET LEGIONNAIRES DISEASE?}

- Legionnaires disease can occur after people have breathed in aerosols that have originated from water sources contaminated with Legionella pneumophila (for example: air conditioning cooling towers, whirlpool spas, showers) or sometimes from soil or potting mix contaminated with Legionella longbaechae bacteria. People may be exposed at home, at work, or in public places.

- It is not spread from person to person.

- The time between the patient's exposure to the bacteria and becoming sick is between two to 10 days.

- Legionnaires disease most often affects middle-aged and older people, particularly those who smoke cigarettes or who have chronic lung disease. Also at increased risk are people whose immune systems are suppressed by medications or diseases such as cancer, kidney failure, diabetes or AIDS.

\section{HOW IS LEGIONNAIRES DISEASE DIAGNOSED AND TREATED?}

- It is difficult to distinguish Legionnaires disease from other types of pneumonia by symptoms alone. Chest $\mathrm{X}$-rays often show pneumonia but the diagnosis requires special tests.

- Tests of blood samples (taken three to six weeks apart), sputum and urine can be helpful for confirming the diagnosis.

- Legionnaires disease can be cured by treatment with antibiotics.

- Patients with Legionnaires disease may be treated in hospital with antibiotics through a drip. Some may need to be in an intensive care unit and may need assistance to breathe by a ventilator.

\section{WHAT CAN BE DONETO PREVENT LEGIONNAIRES DISEASE?}

- Legionella bacteria can be found in many types of water systems. However, the bacteria reproduce to high numbers in warm, stagnant water. Improved design, disinfection and maintenance of cooling towers and plumbing systems limits the growth and spread of Legionella bacteria.

- Legionella longbeachae is common in the soil. Reducing exposure to potting mix dust by following the manufacturers warning present on potting mix labels; and wearing gloves and a mask when using potting mix may help to prevent infection. Wash your hands after handling potting mix or soil, especially before eating, drinking or smoking.

For more information contact your doctor, community health care centre, or your nearest public health unit.

(This fact sheet has been adapted from Centers for Disease Control and Prevention: Legionellosis, which can be viewed at www.cdc.gov/ncidod/dbmd/diseaseinfo/ legionellosis_g.htm.) March 2001 it 